\title{
Risk of recurrent venous thromboembolism in COPD patients: results from a prospective cohort study
}

\author{
Raphael Le Mao ${ }^{1,2}$, Cécile Tromeur ${ }^{1,2}$, Amélie Bazire ${ }^{1}$, Maelenn Gouillou ${ }^{3}$, \\ Marie Guegan ${ }^{2,3}$, Karine Lacut ${ }^{2,3}$, Aurélien Delluc ${ }^{1,2}$, Dominique Mottier ${ }^{2,3}$, \\ Christophe Leroyer ${ }^{1,2}$ and Francis Couturaud ${ }^{1,2,3}$
}

Affiliations: 'Dept de Médecine Interne et Pneumologie, Hôpital La Cavale Blanche, Brest, France. ${ }^{2} E A 3878$, Groupe d'Etude de la Thrombose de Bretagne Occidentale (GETBO), Université Européenne de Bretagne, Brest, France. ${ }^{3}$ Centre d'Investigation Clinique CIC-ISERM1412, Hôpital La Cavale Blanche, Brest, France.

Correspondence: Francis Couturaud, GETBO, EA3878, CIC-INSERM 1412, Dept de Médecine Interne et Pneumologie, CHRU de la Cavale Blanche, Boulevard Tanguy Prigent, 29609 Brest Cedex, France.

E-mail: francis.couturaudachu-brest.fr

@ERSpublications

Patients with venous thromboembolism and COPD do not have a higher risk of recurrence or death http://ow.ly/T9oE30cbIgC

Cite this article as: Le Mao R, Tromeur C, Bazire A, et al. Risk of recurrent venous thromboembolism in COPD patients: results from a prospective cohort study. Eur Respir J 2017; 50: 1700094 [https://doi.org/ 10.1183/13993003.00094-2017].

ABSTRACT We aimed to assess the risk of recurrent venous thromboembolism (VTE) in patients with chronic obstructive pulmonary disease (COPD) following cessation of anticoagulation therapy.

In a prospective cohort of 1468 patients with a documented episode of VTE, followed for up to 5 years after cessation of anticoagulation therapy, the diagnosis of COPD was confirmed in 136 . The main outcome was recurrent VTE. The secondary outcome was overall mortality. Univariate and multivariate analyses were performed to identify the risk factors of recurrence.

Of the 1468 patients included, recurrent VTE was observed in 306 (34 with COPD and 272 without) during a median follow-up period of 36.5 months. The incidence rate of recurrent VTE was $9.1 \%$ (95\% CI 6.5-12.8) for COPD patients and 7.0\% (95\% CI 6.2-7.9) for non-COPD patients. COPD was not associated with an increased risk of VTE recurrence on univariate or multivariate analyses (hazard ratio: 1.0 (95\% CI 0.7-1.4)). The risk of death, adjusted for demographic and clinical characteristics, showed no increase in COPD patients, as compared to non-COPD patients.

In patients with COPD who had an acute episode of VTE, the risk of recurrent VTE was not any higher than that in non-COPD patients. 


\section{Introduction}

Chronic obstructive pulmonary disease (COPD), a progressive disease characterised by a decline in respiratory function that is associated with $90 \%$ of cases of tobacco exposure [1-3], affects approximately 64 million persons worldwide and is the cause of 3 million deaths each year. Projections place COPD as the third leading cause of death in $2030[4,5]$. Venous thromboembolism (VTE) is also a major public health concern, with an annual incidence of about 1.5 per 1000 persons in Europe $[6,7]$, and mortality rate at 3 months of about $10 \%$ [8]. The main complication of VTE is the risk of recurrence (up to $30 \%$ at 5 years) [9], which can be fatal in $10-20 \%$ of cases [10].

Some arguments support an association between COPD and VTE. Indeed, COPD is an inflammatory disease that is associated with a prothrombotic state involving endothelial cell dysfunction and coagulation abnormalities [11-13]. Exposure to nicotine is associated with reduced plasminogen activator inhibitor 1 and increased Factor XIII concentrations [14]. Hypoxia, frequently observed in COPD patients, is associated with an increase in thrombin-antithrombin complexes, prothrombin fragment $1+2$ and interleukin 6 concentrations [15]. In clinical trials, an increased risk of VTE in COPD patients has been reported, particularly in the setting of an acute exacerbation of COPD and in more severe COPD [16-18]. In addition, recent data from the Registro Informatizado de Enfermedad TromboEmbólica (RIETE) registry study suggested that the risk of recurrent VTE and the case-fatality rate of recurrence in patients subjected to COPD therapy were higher than those in the general population during the initial 3 months of anticoagulation of an acute VTE [17, 19]. However, the long-term risk of recurrent VTE and VTE-related death after cessation of anticoagulation remains unknown.

Therefore, we conducted the present prospective study to assess the risk of recurrent VTE in association with COPD after cessation of anticoagulation for an acute episode of VTE.

\section{Materials and methods \\ Study population}

Consecutive patients who had been hospitalised or referred to the Brest University Hospital outpatient VTE clinic between January 1, 1990 and December 31, 2014 were potentially eligible, if they had a documented symptomatic VTE (i.e. an isolated symptomatic deep vein thrombosis (DVT) or a symptomatic pulmonary embolism (PE) either associated or not with DVT) that was initially treated with anticoagulants. Treatment in these patients had been stopped and follow-up was planned without scheduling an end date [20]. The non-inclusion criteria were: age less than 40 years, active cancer, patients with respiratory diseases other than COPD, ongoing anticoagulant therapy, patients without follow-up after cessation of anticoagulant therapy, patients living outside of the Brest district, inability to consent, and patient refusal.

The diagnosis of VTE was performed using objective, standardised and validated criteria [21, 22]. Symptomatic DVT was confirmed in cases of noncompression of the deep veins of the legs using real time B mode ultrasound. Symptomatic PE was confirmed if there was: (i) a high clinical probability and a high-probability ventilation-perfusion lung scan according to the Prospective Investigation of Pulmonary Embolism Diagnosis (PIOPED) criteria; or (ii) a proximal DVT evident by ultrasonography in a patient with symptoms of PE; or (iii) a positive computed tomography pulmonary angiography (CTPA) showing a central filling defect outlined by contrast material, or a complete occlusion in a segmental or more proximal pulmonary artery. VTE was classified as provoked in the presence of at least one of the following major risk factors: surgery or immobilisation in the past 3 months, administration of an oestrogen-containing pill, hormone replacement therapy, pregnancy or the post partum period within the previous 3 months [23]. VTE was considered as unprovoked in the absence of these risk factors.

\section{Identification of COPD patients}

To identify all patients with respiratory diseases, a search by the ICD-10 (International Classification of Diseases, tenth edition) code and keywords was conducted in the Brest University Hospital database and crossed with the cohort study database. The diagnosis of COPD was then confirmed manually for each patient based on medical records and the results of pulmonary function tests (PFT). In cases of missing PFT results, a search was systematically conducted in the pulmonologist's records of the patient. This manual check allowed us to verify proper COPD diagnosis.

COPD was confirmed when PFTs showed a post bronchodilator forced expiratory volume in $1 \mathrm{~s}\left(\mathrm{FEV}_{1}\right) /$ forced vital capacity (FVC) ratio of less than 70\%. COPD patients were then classified according to post bronchodilator FEV1 level, into four stages of severity $(>80 \%, 50-80 \%, 30-49 \%,<30 \%$ or with respiratory insufficiency), corresponding to the severity stages I, II, III and IV of the 2007 Global Initiative for Chronic Obstructive Lung Disease (GOLD) classification [24]. In a few cases for which no PFT was retrieved, any mention of a COPD diagnosis in the pulmonologist's files for the patient was requested. 
Follow-up

All patients were prospectively followed-up for 5 years, with an annual collection of clinical, biochemical and morphological data. Interviews were conducted initially and during follow-up, using the same standardised questionnaire. After the first 3-6 months of anticoagulant treatment, patients were followed systematically once a year through a dedicated visit or phone call. Investigations were made in cases of missing follow-up appointments to assess the health status of the patients.

\section{Outcomes}

The primary endpoint was VTE recurrence within 5 years of follow-up after cessation of anticoagulation therapy. Recurrent VTE was defined by (i) symptomatic non-fatal recurrent PE; (ii) symptomatic recurrent DVT; or (iii) fatal recurrent PE. The diagnosis of recurrent DVT was confirmed using real B mode ultrasound of the leg in cases of initial DVT extension, contralateral recurrence of DVT or ipsilateral DVT recurrence. The diagnosis of recurrent PE was confirmed by: (i) segmental or more proximal thrombus on CTPA; (ii) the presence of at least one new perfusion defect of at least $75 \%$ in contrast with normal ventilation; (iii) clinical suspicion of PE associated with recurrent proximal DVT. The secondary endpoints were overall mortality and the clinical presentation of recurrent VTE. Physicians who were not involved in the medical care of the subjects adjudicated all initial VTE events, recurrences and deaths.

The secondary endpoint was death from any cause within 5 years of follow-up after cessation of anticoagulation therapy. Adjudication was based on medical records, if death occurred during the hospital stay. If death occurred outside of the hospital, the retirement home, general practitioner and relatives of the patient were contacted to collect information on the cause of death. For patients lost to follow-up, the status (dead or living) of the patient was determined through consultation with the City Hall birth registers. The members of the research team who were not involved in patient care carried out the death adjudication. The causes of death were classified into four categories: (i) certainly due to PE, if an autopsy was performed or if death occurred within the 7 days following an objectively diagnosed PE recurrence; (ii) $\mathrm{PE}$ as probable cause of death, if there was no alternative diagnostic hypothesis and a strong clinical suspicion; (iii) death unlikely due to PE, if there was an alternative diagnosis; (iv) death not related to PE, in cases of autopsy diagnosis or of another identified cause of death. Data on the occurrence of sudden death, curative anticoagulation therapy (including cessation date) and major comorbidities (active cancer, atherosclerotic arterial disease, coronary disease, stroke or transient ischaemic attack, respiratory failure, heart failure or other specified) were also collected.

\section{Laboratory methods}

Blood was collected in $0.05 \mathrm{M}$ EDTA for DNA analysis. Genomic DNA was extracted from peripheral leukocytes in EDTA-anticoagulated blood, using a commercially available DNA isolation kit (Qiagen, Courtaboeuf, France). Genotype was determined for the FV G1691A gene mutation [Factor V Leiden $(\mathrm{FVL})]$ and for the prothrombin G20210A gene variation, as previously described $[25,26]$.

\section{Statistical analyses}

Continuous variables were expressed as mean \pm SD and median (interquartile range (IQR)); categorical variables were expressed as numbers and percentages. The $t$-test was used to compare means between groups in cases of normal distribution, and the Mann-Whitney test was used in cases of non-normal distribution. The Chi-squared test or exact Fisher test was used to compare proportions, as appropriate.

The rates of recurrent VTE and death were calculated using Kaplan-Meier survival analyses. Univariate analysis was performed to identify risk factors of recurrent VTE and death, using the log-rank test. Multivariate analyses were performed using a Cox regression model in two stages, for the risk of recurrent VTE, as well as for the risk of death in association with COPD. The first multivariate model was constructed by including variables with distributions that were statistically different $(p<0.05)$ between the two groups. The second multivariate model was constructed by including: (i) variables associated with an increased risk of recurrence or death in univariate analysis, with a $\mathrm{p}$-value $<0.15$ and frequency $>3 \%$; and (ii) variables with a distribution that was significantly different between the two groups $(\mathrm{p}<0.05)$. In multivariate models, risk factors were considered independent for a p-value $<0.05$. All tests were two-sided. Statistical analyses were performed using the SAS version 9.4 software (SAS, Marlow, UK).

\section{Ethics statement}

The Ethics Committee of Brest University Hospital approved the study protocol. Written informed consent was obtained from all participants prior to inclusion. 


\section{Results}

Between January 1990 and December 2014, 4316 patients with objectively confirmed VTE were enrolled and followed-up prospectively in the cohort. Of this number, 2848 presented one or more predefined exclusion criteria (figure 1). In the remaining 1468 patients included in the present analysis, 136 had COPD (diagnosed in 107 patients based on PFT, and 29 based on pulmonologist assessment). The median follow-up (IQR) was 36.5 months (10.1-60.0) in the overall study population, 30.4 months $(6.8-60.0)$ in patients with COPD and 37.1 months (10.3-60.0) in patients without COPD ( $\mathrm{p}=0.29)$.

\section{Baseline characteristics}

Demographic and clinical characteristics at inclusion are presented in table 1. COPD patients, as compared to non-COPD patients, were generally older, mostly men, at higher vascular risk (smoking, arterial history), had more frequent initial VTE presenting as PE rather than DVT and had greater initial unprovoked VTE. No differences were observed between the two groups regarding body mass index (BMI), personal and family history of VTE, and average length of the initial anticoagulant therapy.

\section{Risk of recurrent venous thromboembolism}

Among the entire cohort, recurrent VTE occurred in 306 patients during follow-up after anticoagulation discontinuation (annual incidence of 7.2\% (95\% CI 6.4-8.0)); 34 of these recurrences occurred in COPD patients (annual incidence of 9.1\% (95\% CI 6.5-12.8)) and 272 in non-COPD patients (annual incidence of $7.0 \%$ (95\% CI 6.2-7.9)) (table 2). Among the 306 recurrences of VTE, 131 (43.1\%) were isolated DVT and 173 (56.9\%) were PE (with or without DVT). Data on VTE location were missing in two patients.

In univariate analysis, COPD was not associated with an increased risk of recurrence (Hazard Ratio [HR] 1.29 (95\% CI, 0.91-1.85; $\mathrm{p}=0.16$ )) (table 2). Unadjusted recurrence-free survival curves are presented in figure 2 .

In multivariate model 1 , which included baseline characteristics that were distributed differently between COPD and non-COPD patients, the risk of recurrent VTE showed no significant increase in COPD patients as compared to other patients (HR 0.99 (95\% CI 0.68-1.43); p=0.96). In multivariate model 2, which included baseline characteristics that were distributed differently between COPD and non-COPD patients, the predictors of recurrent VTE were similar to those found in univariate analysis (HR 0.99 (95\% CI 0.68-1.43); $\mathrm{p}=0.95$ ) (table 2).

Predictive factors that were associated with an increased risk of recurrent VTE in univariate and multivariate analyses are presented in table 2. The main risk factors of recurrence were older age, the absence of provoking risk factors of VTE and clinical presentation as PE during the acute phase of VTE. Sensitivity analyses performed in subgroups of patients with unprovoked VTE or in patients with symptomatic PE also confirmed that COPD was not associated with an increased risk of recurrent VTE (data not shown).

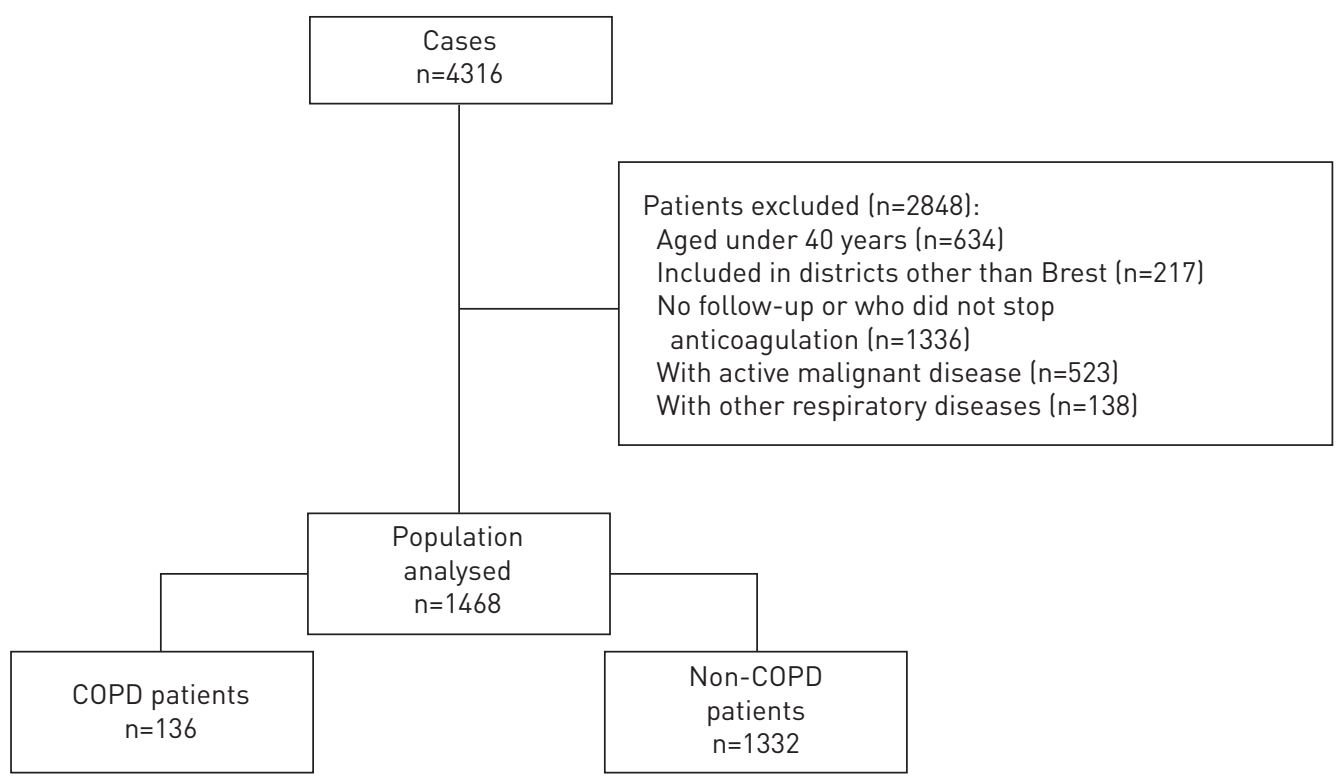

FIGURE 1 Population analysed and excluded patients. COPD: chronic obstructive pulmonary disease. 


\begin{tabular}{|c|c|c|c|}
\hline Variables & COPD & No COPD & p-value \\
\hline Subjects $\mathrm{n}$ & 136 & 1332 & \\
\hline Females & $43(31.6)$ & $741(55.6)$ & $<0.001$ \\
\hline Age years & $68.7(11.1)$ & $65.3(13.8)$ & 0.001 \\
\hline \multicolumn{4}{|l|}{ Age range years } \\
\hline $40-59$ & 27 (19.9) & $464(34.8)$ & \multirow[t]{3}{*}{0.001} \\
\hline $60-74$ & $63(46.3)$ & $461(34.6)$ & \\
\hline$>75$ & 46 (33.8) & $407(30.6)$ & \\
\hline \multicolumn{4}{|l|}{ VTE presentation } \\
\hline DVT & 33 (24.3) & $623(46.8)$ & \multirow[t]{2}{*}{$<0.001$} \\
\hline PE with/without DVT & 103 (75.7) & 709 (53.2) & \\
\hline Provoked VTE & $21(15.4)$ & $351(26.5)$ & 0.005 \\
\hline Immobilisation after surgery & $17(12.5)$ & 229 (17.2) & 0.16 \\
\hline Oestrogen-containing pill & $0(0.0)$ & $71(9.6)$ & 0.026 \\
\hline HRT & 4 (9.3) & $71(9.6)$ & 1.00 \\
\hline Pregnant or post partum & $0(0.0)$ & $4(0.5)$ & 1.00 \\
\hline Thrombophilia & $15(12.0)$ & $207(17.1)$ & 0.15 \\
\hline Smoking & $89(65.4)$ & 433 (32.5) & $<0.001$ \\
\hline BMI & $26.5 \pm 5.2$ & $26.7 \pm 4.8$ & 0.73 \\
\hline VKA duration & $11.7 \pm 16.4$ & $9.4 \pm 13.1$ & 0.12 \\
\hline$<6$ months & $55 \pm 40.4$ & $631 \pm 47.4$ & 0.12 \\
\hline$\geqslant 6$ months & $81 \pm 59.6$ & $700 \pm 52.6$ & \\
\hline Previous VTE & $23(16.9)$ & 237 (17.9) & 0.78 \\
\hline Cardiovascular history & $35(25.7)$ & $169(12.7)$ & $<0.001$ \\
\hline Family history of VTE & 26 (20.8) & $346(28.1)$ & 0.08 \\
\hline \multicolumn{4}{|l|}{ FEV $1 \%$ pred } \\
\hline$>80 \%$ & $11(8.1)$ & & \\
\hline $50-80 \%$ & $49(36.0)$ & & \\
\hline $30-49 \%$ & $21(15.4)$ & & \\
\hline LTOT or $<30 \%$ & $26(19.1)$ & & \\
\hline \multicolumn{4}{|l|}{ Follow-up period months } \\
\hline Mean $\pm S D$ & $32.9 \pm 24.4$ & $35.1 \pm 23.6$ & \multirow[t]{2}{*}{0.29} \\
\hline Median (interquartile range) & $30.4(6.8-60.0)$ & $37.1(10.3-60.0)$ & \\
\hline \multicolumn{4}{|c|}{$\begin{array}{l}\text { Data are presented as } \mathrm{n}(\%) \text { or mean } \pm \mathrm{SD} \text {, unless otherwise stated. COPD: chronic obstructive pulmonary } \\
\text { disease; VTE: venous thromboembolism; DVT: deep vein thrombosis; PE: pulmonary embolism; HRT: } \\
\text { hormone replacement therapy; BMI: body mass index; VKA: vitamin K antagonist; FEV1: forced expiratory } \\
\text { volume in } 1 \mathrm{~s} \text {; LTOT: long-term oxygen therapy. \#: immobilisation after surgery, oestrogen-containing pill, } \\
\text { pregnancy or post partum, HRT; }{ }^{1}: \text { thrombophilia was factor } V \text { Leiden or the G20210A prothrombin gene } \\
\text { variant. }\end{array}$} \\
\hline
\end{tabular}

\section{Clinical presentation of VTE recurrences}

In the 656 patients who had an initial DVT, recurrence of DVT occurred in 69.1\% (76 out of 110) of cases, and this percentage was not significantly different between COPD and non-COPD patients $(62.5 \%$ (5 out of 8 ) and $69.6 \%$ (71 out of 102 ), respectively). Similarly, in the 812 patients who had an initial PE, recurrence of PE occurred in $71.6 \%$ (139 out of 194) of cases, and this percentage was not significantly different between COPD and non-COPD patients (69.2\% (18 out of 26 ) and $72.0 \%$ (121 out of 168), respectively). Furthermore, in COPD patients, the proportion of patients with recurrent VTE was not significantly different among the various stages of severity $(15.3 \%, 23.5 \%, 23.8 \%$ and $40.7 \%$ in GOLD I, II, III and IV groups, respectively) ( $\mathrm{p}=0.3)$.

\section{Mortality}

During the median follow-up of 3 years, deaths from any cause occurred in 225 (15.3\%) patients of the overall cohort: 32 out of 136 in the COPD group (23.5\%) and 193 out of 1332 in the non-COPD group $(14.5 \%)(p=0.005)$. In univariate analysis, there was an increased risk of death in COPD patients as compared to non-COPD patients (HR 1.62 (95\% CI 1.11-2.34) p=0.012) (figure 3). After adjustment for baseline characteristics that were distributed differently between the two groups, the risk of death was no longer found to be higher in COPD patients, as compared to other patients (HR 0.97 (95\% CI 0.67-1.40); $\mathrm{p}=0.85)$. 
TABLE 2 Risk factors for recurrent venous thromboembolism (VTE)

\begin{tabular}{|c|c|c|c|c|c|c|}
\hline Variables & $\begin{array}{l}\text { Univariate } \\
\text { analysis }\end{array}$ & p-value & $\begin{array}{c}\text { Multivariate } \\
\text { model } 1^{\#}\end{array}$ & p-value & $\begin{array}{l}\text { Multivariate } \\
\text { model } 2^{\text {? }}\end{array}$ & p-value \\
\hline \multicolumn{7}{|l|}{ Age range years } \\
\hline $40-59$ & Ref. & & Ref. & & Ref. & \\
\hline $60-74$ & $1.8(1.4-2.5)$ & $<0.001$ & $1.7(1.3-2.3)$ & $<0.001$ & $1.7(1.2-2.3)$ & 0.001 \\
\hline$\geqslant 75$ & $2.4(1.8-3.3)$ & $<0.001$ & $2.3(1.6-3.1)$ & $<0.001$ & $2.2(1.6-3.1)$ & $<0.001$ \\
\hline COPD & $1.3(0.9-1.8)$ & 0.16 & $1.0(0.7-1.4)$ & 0.96 & $1.0(0.7-1.4)$ & 0.95 \\
\hline BMI & $1.0(1.0-1.0)$ & 0.51 & & & & \\
\hline Provoked VTE & $0.5(0.4-0.6)$ & $<0.001$ & $0.6(0.4-0.8)$ & $<0.001$ & $0.6(0.4-0.8)$ & 0.001 \\
\hline Male/female & $1.0(0.8-1.3)$ & 0.99 & $1.0(0.7-1.3)$ & 0.77 & $1.0(0.8-1.3)$ & 0.92 \\
\hline Cardiovascular history & $1.1(0.8-1.5)$ & 0.63 & $0.8(0.6-1.2)$ & 0.32 & $0.8(0.6-1.2)$ & 0.29 \\
\hline Tobacco & $1.1(0.8-1.4)$ & 0.56 & $1.3(1.0-1.7)$ & 0.07 & $1.3(1.0-1.7)$ & 0.088 \\
\hline Family history of VTE & $1.1(0.8-1.4)$ & 0.57 & & & & \\
\hline Personal history of VTE & $1.3(1.0-1.7)$ & 0.062 & & & $1.3(1.0-1.7)$ & 0.083 \\
\hline Thrombophilia $^{+}$ & $0.9(0.7-1.3)$ & 0.58 & & & & \\
\hline Initial PE versus DVT & $1.5(1.2-1.9)$ & $<0.001$ & $1.4(1.1-1.8)$ & 0.008 & $1.4(1.1-1.8)$ & 0.006 \\
\hline Anticoagulation duration & $1.0(1.0-1.0)$ & 0.02 & & & $1.0(1.0-1.0)$ & 0.29 \\
\hline
\end{tabular}

Data are presented as hazard ratio $(95 \% \mathrm{CI})$, unless otherwise stated. Ref.: reference; COPD: chronic obstructive pulmonary disease; BMI: body mass index; PE: pulmonary embolism; DVT: deep vein thrombosis. \#: multivariate analysis adjusted for patient characteristics; ": multivariate analysis adjusted for patient characteristics and recurrence risk factors; ${ }^{+}$: factor V Leiden or the G20210A prothrombin gene variant.

Mortality rates were significantly different according to the COPD severity stages $(15.4 \%, 13.7 \%, 19.1 \%$ and $44.4 \%$ of deaths in GOLD I, II, III and IV groups, respectively) ( $\mathrm{p}=0.023)$.

The causes of death are presented in table 3. Adjudicated causes of death were available for 17 (53.1\%) COPD patients and 101 (52.3\%) non-COPD patients. Three non-COPD patients died from PE; four (12.5\%) COPD patients and $16(8.3 \%)$ non-COPD patients probably died from PE. No significant differences were observed between the two groups regarding the causes of death $(p=0.75)$. The most frequent causes of death were acute respiratory failure, PE, cancer and septic shock.

\section{Discussion}

In this prospective cohort including 1468 patients with an acute episode of symptomatic VTE, followed-up after cessation of anticoagulation therapy for a median time of 3 years, the presence of a underlying COPD was not associated with an increased risk of VTE recurrence, nor with increased overall mortality.

A few previous studies investigated the potential association between COPD and VTE recurrence. In the case-control study of HEIT et al. [27] that aimed to identify predictive factors of recurrence in 1262 patients with the first episode of VTE, no increased risk of recurrence was observed in patients with chronic lung diseases; COPD patients were included in a set of heterogeneous respiratory diseases and no

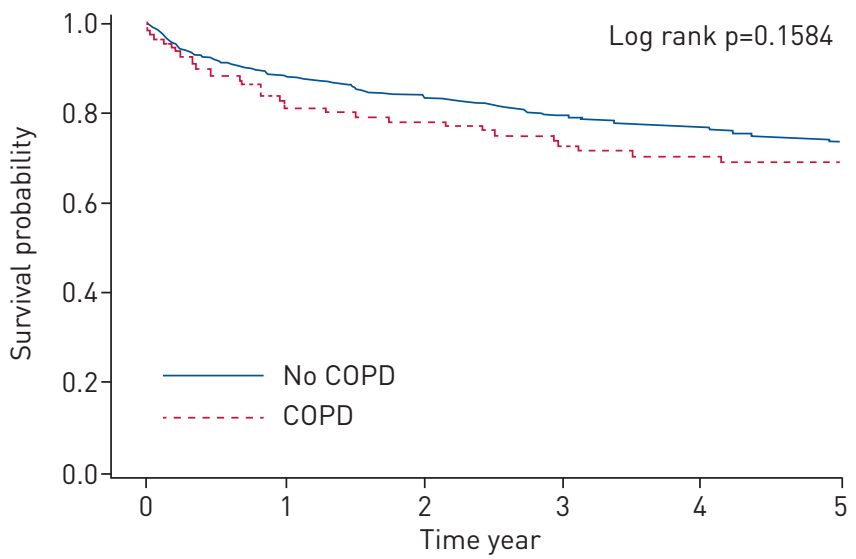

FIGURE 2 Unadjusted 5-year recurrence-free survival curves (product-limit survival estimates). COPD: chronic obstructive pulmonary disease. 


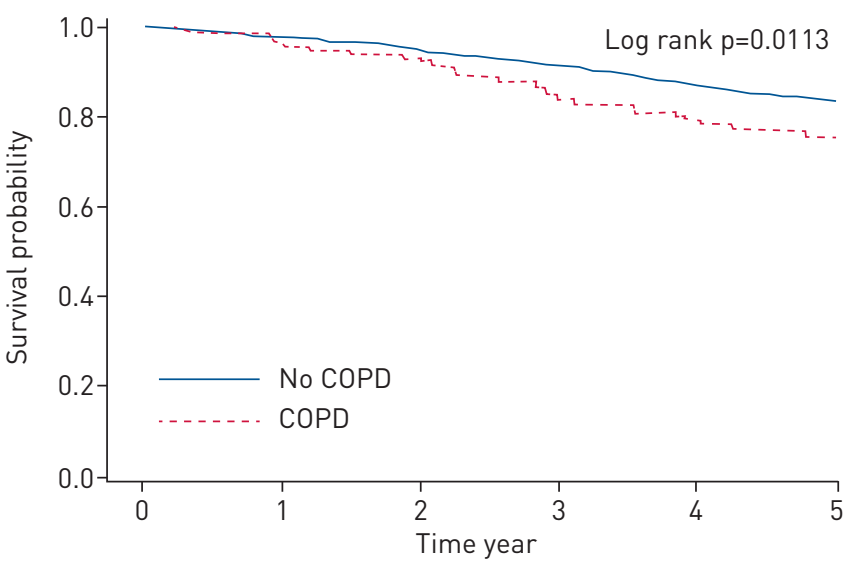

FIGURE 3 Unadjusted 5-year survival curves (product-limit survival estimates). COPD: chronic obstructive pulmonary disease.

information was provided on the measurements of PFTs. In the "RIETE" registry of 28920 patients, only the trend towards an increased risk of recurrence was observed in COPD patients, as compared to non-COPD patients [16]. However, later in the same study, the risk of recurrent VTE was estimated over the first 3 months of anticoagulation therapy, and no data was provided following the cessation of anticoagulation treatment. Findings from the present cohort study should be interpreted with two different selection criteria in mind: ascertainment of COPD diagnosis with PFTs and exclusion of patients with cancer or other respiratory diseases, to reduce the risk of confounding factors.

Consistent with the results of many randomised trials, patients from our study with unprovoked VTE had a two-fold increase in the risk of recurrence, as compared to patients with provoked VTE [27-30]. This observation was not related to treatment duration, consistent with the results of randomised trials that have compared different durations of anticoagulation therapy in patients with unprovoked VTE [28-30]. Our study also shows that older patients (i.e. age $\geqslant 60$ years) had a higher risk of recurrent VTE. This latter finding is also in accordance with the observations of other prospective cohorts [8, 9, 27]. Furthermore, we observed a higher risk of recurrent VTE after PE, as compared to DVT. Similar observations have also been reported by PUURUNEN et al., [31] in the Framingham cohort. However, our cohort recruited a majority of patients with PE, because DVT patients were being managed mostly in an ambulatory setting. Therefore, our findings might have been over-estimated.

\section{TABLE 3 Causes of death}

COPD

Subjects $n$

Certainly not due to PE

Certainly due to PE

Probably not due to PE

Probably due to PE

Missing data

Causes of death ${ }^{\#}$

Acute cardiac failure

Acute respiratory failure

Arrhythmia

Bleeding

Cancer

Kidney failure

Myocardial infarction

Septic shock

Stroke

Trauma

32

$1(3.1)$

$0(0)$

12 (37.5)

4 (12.5)

15 (46.9)

1 (3.1)

$5(15.3)$

$0(0)$

1 (3.1)

2 (6.3)

$0(0)$

1 (3.13)

$2(6.3)$

$5(2.6)$

$0(0)$
No COPD

193

$17(8.1)$

$3(1.6)$

65 (33.7)

$16(8.3)$

$92(47.7)$

12 (6.22)

$20(10.4)$

$1(0.5)$

$12(6.2)$

$13(6.7)$

$1(0.5)$

$4(2.1)$

$12(6.2)$

$1(3.1)$

2 (1.0)

Data are presented as $\mathrm{n}(\%)$, unless otherwise stated. COPD: chronic obstructive pulmonary disease; PE: pulmonary embolism. ${ }^{\#}$ : definite causes, probably not due to PE. 
Although a greater number of deaths occurred during follow-up in COPD patients, the risk of dying was not different in non-COPD patients, after adjusting for baseline characteristics. To date, no previous study has evaluated long-term mortality in COPD patients with VTE after cessation of anticoagulation therapy. Most of the prospective trials have evaluated mortality during the first few months of anticoagulation. In the RIETE registry, a significant difference in mortality rates was noted at 3 month in COPD patients (10.8\%) versus non-COPD patients (7.6\%), considering the high proportion $(20 \%)$ of cancer patients included in that study [19]. Similarly, prospective trials that have led to derivative prognosis scores for PE have reported chronic respiratory disease as a risk factor for death during the first few months of treatment.

The strengths of our study include the following: (i) prospective and consecutive enrolment of patients with documented VTE; (ii) COPD assessment in $79 \%$ of cases based on PFT results in accordance with international recommendations [4] and the exclusion of patients with respiratory diseases other than COPD; (iii) the use of predefined, validated and objective criteria for all cases of recurrent VTE, which were adjudicated by physicians who were not involved in patient care; (iii) the use of predefined criteria for assessing the cause of death, which was objectively adjudicated; (iv) a relatively long median follow-up period of 3 years, during which patients either had scheduled visits or received questionnaires every 6 12 months, as pre-specified in the cohort study.

Limitations of our study are mainly related to selection biases. First, we cannot exclude the under-diagnosis of COPD, although the COPD prevalence of $10.2 \%$ in our cohort was close to the value of $10 \%$ reported in French subjects over 45 years old [32]. Second, as patients were referred to our tertiary University Hospital of Brest, they might have had other comorbidities and a more severe clinical presentation of VTE (i.e. PE rather than DVT); however, they could have had a more favourable prognosis than expected, owing to the expertise of an experienced team in the field of VTE. This possibility, in addition to the relatively small number of COPD patients included, could have led to an underestimation of the risk of death and recurrent VTE in COPD patients. The conclusions that we could draw from this study are therefore mostly applicable to inpatient settings.

Another selection bias could have been introduced with the exclusion of patients on long-term anticoagulation, who were estimated to have a high risk of recurrence by physicians. This could have had an impact on both severity and mortality in our cohort. Research studies in such populations, including patients with active cancer, deserves specific attention [33-35]. Lastly, although we attempted to ascertain the cause of death in all patients, we were unable to establish this for the majority of patients, a difficulty that we share with most other European settings.

\section{Conclusion}

In this large prospective study, we found that, after cessation of anticoagulation therapy, the risk of recurrent VTE in patients with COPD was not any greater than that of patients without respiratory disease, during a median follow-up of 3 years. In addition, the risk of death showed no increased in COPD patients as compared to other patients. Consequently, our observations suggest that the treatment strategy in patients with VTE and COPD should not differ from that in patients without COPD, in terms of duration of anticoagulation therapy and follow-up.

\section{Acknowledgements}

The coordinating and methods center was the Groupe d'Etude de la Thrombose de Bretagne Occidentale (GETBO), EA 3878, CIC INSERM 1412, University Hospital Centre, Brest, France. The following institutions and staff participated in this study. Brest University Hospital Centre, Brest, France: M. Le Hir, A. Le Brestec, A. Loussouarn and C. Daguet; INSERM UMR 1078, Laboratory Molecular Genetic, Brest, France: C. Ferec, C. Le Maréchal, E. Génin.

Author contributions were as follows. F. Couturaud had full access to all data in the study and took responsibility for the integrity of the data and accuracy of the data analysis; conception and design: F. Couturaud and R. Le Mao; analysis and interpretation of the data: R. Le Mao, C. Tromeur, A. Bazire, M. Gouillou, M. Guegan, K. Lacut, A. Delluc, D. Mottier, C. Leroyer and F. Couturaud; drafting of the article: R. Le Mao, C. Tromeur, A. Bazire, K. Lacut, A. Delluc, D. Mottier, C. Leroyer and F. Couturaud; critical revision of the article for important intellectual content: R. Le Mao, C. Tromeur, A. Bazire, M. Gouillou, K. Lacut, A. Delluc, D. Mottier, C. Leroyer and F. Couturaud; final approval of the article: R. Le Mao, C. Tromeur, A. Bazire, M. Gouillou, M. Guegan, K. Lacut, A. Delluc, D. Mottier, C. Leroyer and F. Couturaud; provision of study material or patients: R. Le Mao, C. Tromeur, A. Bazire, M. Guegan, K. Lacut, A. Delluc, D. Mottier, C. Leroyer and F. Couturaud; obtaining funding: F. Couturaud, D. Mottier and C. Leroyer; administrative, technical and logistic support: F. Couturaud, C. Leroyer and D. Mottier; collection and assembly of data: R. Le Mao, F. Couturaud, M. Gouillou, C. Tromeur and C. Leroyer.

\section{References}

1 Løkke A, Lange P, Scharling H, et al. Developing COPD: a 25 year follow up study of the general population. Thorax 2006; 61: 935-939. 
2 Eisner MD, Anthonisen N, Coultas D, et al. An official American Thoracic Society public policy statement: novel risk factors and the global burden of chronic obstructive pulmonary disease. Am J Respir Crit Care Med 2010; 182: 693-718.

3 Jindal SK, Aggarwal AN, Chaudhry K, et al. A multicentric study on epidemiology of chronic obstructive pulmonary disease and its relationship with tobacco smoking and environmental tobacco smoke exposure. Indian J Chest Dis Allied Sci 2006; 48: 23-29.

4 World Health Organization. Chronic obstructive pulmonary disease (COPD). www.who.int/mediacentre/ factsheets/fs315/en/ Date last updated: November 2016. Date last accessed: July 8, 2015.

5 Rycroft CE, Heyes A, Lanza L, et al. Epidemiology of chronic obstructive pulmonary disease: a literature review. Int J Chron Obstruct Pulmon Dis 2012; 7: 457-494.

6 Naess IA, Christiansen SC, Romundstad P, et al. Incidence and mortality of venous thrombosis: a population-based study. J Thromb Haemost 2007; 5: 692-699.

7 Delluc A, Tromeur C, Le Ven F, et al. Current incidence of venous thromboembolism and comparison with 1998: a community-based study in Western France. Thrombo Haemost 2016; 116: 967-974.

8 Heit JA, Mohr DN, Silverstein MD, et al. Predictors of recurrence after deep vein thrombosis and pulmonary embolism: a population-based cohort study. Arch Intern Med 2000; 160: 761-768.

9 Prandoni P, Noventa F, Ghirarduzzi A, et al. The risk of recurrent venous thromboembolism after discontinuing anticoagulation in patients with acute proximal deep vein thrombosis or pulmonary embolism. A prospective cohort study in 1,626 patients. Haematologica 2007; 92: 199-205.

10 Carrier M, Le Gal G, Wells PS, et al. Systematic review: case-fatality rates of recurrent venous thromboembolism and major bleeding events among patients treated for venous thromboembolism. Ann Intern Med 2010; 152: 578-589.

11 Saghazadeh A, Hafizi S, Rezaei N. Inflammation in venous thromboembolism: cause or consequence? Int Immunopharmacol 2015; 28: 655-665.

12 Jankowski M, Undas A, Kaczmarek P, et al. Activated factor XI and tissue factor in chronic obstructive pulmonary disease: links with inflammation and thrombin generation. Thromb Res 2011; 127: 242-246.

13 Cella G, Sbarai A, Mazzaro G, et al. Plasma markers of endothelial dysfunction in chronic obstructive pulmonary disease. Clin Appl Thromb Hemost 2001; 7: 205-208.

14 Tapson VF. The role of smoking in coagulation and thromboembolism in chronic obstructive pulmonary disease. Proc Am Thorac Soc 2005; 2: 71-77.

15 Sabit R, Thomas P, Shale DJ, et al. The effects of hypoxia on markers of coagulation and systemic inflammation in patients with COPD. Chest 2010; 138: 47-51.

16 Bertoletti L, Quenet S, Mismetti P, et al. Clinical presentation and outcome of venous thromboembolism in COPD. Eur Respir J 2012; 39: 862-868.

17 Tillie-Leblond I, Marquette C-H, Perez T, et al. Pulmonary embolism in patients with unexplained exacerbation of chronic obstructive pulmonary disease: prevalence and risk factors. Ann Intern Med 2006; 144: 390-396.

18 Børvik T, Brækkan SK, Enga K, et al. COPD and risk of venous thromboembolism and mortality in a general population. Eur Respir J 2016; 47: 473-481.

19 Bertoletti L, Quenet S, Laporte S, et al. Pulmonary embolism and 3-month outcomes in 4036 patients with venous thromboembolism and chronic obstructive pulmonary disease: data from the RIETE registry. Respir Res 2013; 14: 75.

20 Delluc A, Tromeur C, Le Moigne E, et al. Lipid lowering drugs and the risk of recurrent venous thromboembolism. Thromb Res 2012; 130: 859-863.

21 Konstantinides S. Clinical practice. Acute pulmonary embolism. N Engl J Med 2008; 359: 2804-2813.

22 Kearon C, Julian JA, Newman TE, et al. Noninvasive diagnosis of deep venous thrombosis. McMaster Diagnostic Imaging Practice Guidelines Initiative. Ann Intern Med. 1998; 128: 663-677.

23 Kearon C, Akl EA, Ornelas J, et al. Antithrombotic therapy for VTE disease: CHEST guideline and expert panel report. Chest 2016; 149: 315-352.

24 Rabe KF, Hurd S, Anzueto A, et al. Global strategy for the diagnosis, management, and prevention of chronic obstructive pulmonary disease: GOLD executive summary. Am J Respir Crit Care Med 2007; 176: 532-555.

25 Bertina RM, Koeleman BPC, Koster T, et al. Mutation in blood coagulation factor V associated with resistance to activated protein C. Nature 1994; 369: 64-67.

26 Poort SR, Rosendaal FR, Reitsma PH, et al. A common genetic variation in the 3'-untranslated region of the prothrombin gene is associated with elevated plasma prothrombin levels and an increase in venous thrombosis. Blood 1996; 88: 698-703.

27 Heit JA, Lahr BD, Ashrani AA, et al. Predictors of venous thromboembolism recurrence, adjusted for treatments and interim exposures: a population-based case-cohort study. Thromb Res 2015; 136: 298-307.

28 Agnelli G, Prandomi P, Becattini C, et al. Extended oral anticoagulant therapy after a first episode of pulmonary embolism. Ann Intern Med 2003; 139: 19-25.

29 Agnelli G, Prandoni P, Santamaria MG, et al. Three months versus one year of oral anticoagulant therapy for idiopathic deep vein thrombosis. N Eng J Med 2001; 345: 165-169.

30 Couturaud F, Sanchez O, Pernod G, et al. Six months vs extended oral anticoagulation after a first episode of pulmonary embolism: the PADIS-PE randomized clinical trial. JAMA 2015; 314: 31-40.

31 Puurunen MK, Gona PN, Larson MG, et al. Epidemiology of venous thromboembolism in the Framingham Heart Study. Thromb Res 2016; 145: 27-33.

32 Fuhrman C, Delmas M-C, pour le groupe épidémiologie et recherche clinique de la SPLF. [Epidemiology of chronic obstructive pulmonary disease in France]. Rev Mal Respir 2010; 27: 160-168.

33 Cohen AT, Agnelli G, Anderson FA, et al. Venous thromboembolism (VTE) in Europe. The number of VTE events and associated morbidity and mortality. Thromb Haemost 2007; 98: 756-764.

34 Heit JA. Epidemiology of venous thromboembolism. Nat Rev Cardiol 2015; 12: 464-474.

35 Deng A, Galanis T, Graham MG. Venous thromboembolism in cancer patients. Hosp Pract (1995) 2014; 42: $24-33$. 